\section{Novel schemes skirt NICE barrier}

A $£ 600$ (\$968) million fund that gives cancer specialists the power to prescribe drugs not recommended by the UK's National Institute for Health and Clinical Excellence (NICE) in London could clear the path of expensive biotech drugs to market. At the same time, a clarification of how medical practitioners and hospitals can engage in risk-sharing agreements with drugmakers - in all areas, not just cancer-could benefit companies producing innovative biologics, although the systems' intricacies could be hard to navigate.

In April 2011, the UK Government launched the Cancer Drugs Fund, worth $£ 200$ (\$322) million a year over three years, to facilitate patient access to innovative cancer therapies before the branded drug price reform expected at the end of 2013. Cancer specialists within the UK's National Health Service and supported by their hospital trust can apply for funds to treat individual patients with cancer drugs not agreed upon by NICE because they have yet to be appraised, are deemed too expensive or are not approved for the patient's specific subgroup.

Panels of physicians will undertake funding decisions and will also be encouraged to create lists of drugs and indications eligible for routine funding from the Cancer Drugs Fund. According to a Department of Health spokesperson, the fund will operate by allowing strategic health authorities and local trusts to make decisions on reimbursement, rather than making them centrally.

Also, a recently published clarification on drug pricing and risk sharing may have a positive impact on the biotech industry. The Code of Practice set by the Association of the British Pharmaceutical Industry already incorporates provision for full or partial refund of the price paid for a medicine "if the outcome of the use of the medicine in a patient fails to meet certain criteria." Vicky Edgecombe, head of communications at the Prescription Medicines Code of Practice Authority, adds that "risk-

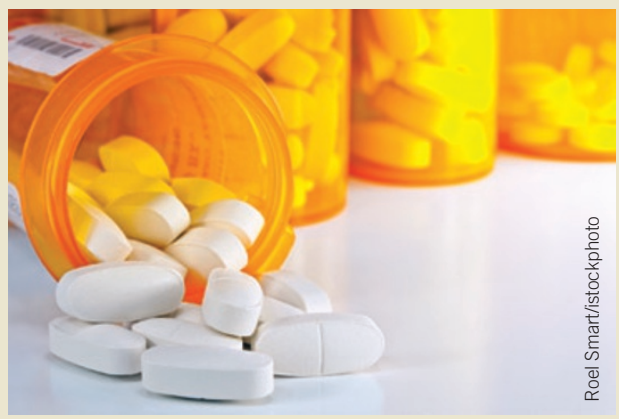

Costly cancer treatments could be made available through the newly launched Cancer Drug Fund. sharing agreements have always been allowed under the code. The code is a directional document, not a proscriptive one."

Agreements can be instituted by individual general practitioners, as well as by hospitals or trusts. Some have raised concerns that they could be open to abuse but the code clearly states that any refund or recompense goes back to the health authority or trust, rather than to the individual health professionals or practices.

Both the cancer fund and the risk-sharing clarification are likely to affect the biotech industry. "For the smaller companies in this space, anything that improves perceived or actual access for patients, by removing the barriers to NICE approval, and adds a degree of flexibility will be beneficial," says Mike Mitchell, healthcare analyst at Seymour Pierce, London. Susan Kilby, MacMillan Network Pharmacist, Guilford, UK, agrees: "From the perspective of companies, patient-access programs and risk-sharing agreements do get around the NICE barrier."

Even so, the administrative work involved in risk-sharing and patient-access programs could also prove a deterrent for biotech companies, as they tend to be smaller and the burden would be disproportionately greater than for larger companies. "The issue associated with patient-access programs like these is that while they offer a potential route to market that avoids the value-based decisions associated with NICE, they increase the level of fragmentation of the approval process and make the marketplace more complex, which may make it harder for the smaller biotech companies to navigate," says Mitchell. Keith Powell, Chairman for London-based Domainex, adds that although the cancer fund is "a worthwhile program, its value is not in helping small biotechs." If these companies have a drug, he adds, "they will almost certainly be getting it to market through a much larger player."

Another downside is that NICE approval normally goes a long way toward validating a drug. By circumventing this recommendation process, companies lose this validation, and with it a valuable marketing tool.

\section{IN brief}

\section{Cisgenic crop exemption}

Cisgenic plants could be allowed on the market without US Environmental Protection Agency (EPA) approval under a proposed rule change aimed at reducing the regulatory burden for biotech crops. Cisgenic plants are formed by moving genetic material between sexually compatible species, such as from one variety of corn to another, using molecular biology tools. Some industry supporters say they are hopeful that cisgenic exemption is a first step in a broader effort by EPA to fully accept biotech crops as safe, and to exempt all genetically modified (GM) plants. "The usefulness of the proposed exemption to crop developers will depend on how narrowly the cisgenic exemption is defined," says Adrianne Massey, managing director of scientific and regulatory affairs at the Biotechnology Industry Organization in Washington, DC. "We will learn these details only after EPA publishes the proposed rule and requests comments." At press time, the EPA had not released the draft rule to the public. The agency in March shared a draft with the US Department of Agriculture (USDA), which also regulates biotech crops, and the US Department of Health and Human Services, for their review. According to EPA documents, the purpose of the exemption is to "encourage research and development of useful biotechnology" and to reduce the number of GM plants seeking registration. "It would not be surprising for USDA to take a similar action," says Doug GurianSherman of the Union of Concerned Scientists in Cambridge, Massachusetts. Emily Waltz

\section{EU tolerates GM}

On June 24 the European Commission took a baby step forward by harmonizing regulations on unapproved genetically modified (GM) organisms found in trace amounts in animal feed imports. Up to $0.1 \%$ GM products will now be allowed in feed, in a move aimed at easing feed shortage fears. Lack of synchronicity in GM regulations between importing and exporting countries means that when traces of GM organisms find their way into feed and food, shipments are blocked and the risk of supply disruptions mounts. Val Giddings, senior fellow with the Information Technology and Innovation Foundation in Washington, DC, says, "The biotech industry will be affected indirectly. The new rules will make the lives of their biggest customers easier...They are the ones who ship harvest around the world and bear the brunt of exposure when detection methods of unprecedented power are linked with a regulatory regime unhinged from risk, reason or reality." The new threshold will apply only under certain conditions (for instance, authorization pending in EU for over three months), and does not apply to food, however. "It's a limited stopgap, doing nothing for food and not enough for feed," Giddings adds. According to Carel du Marchie Sarvaas, from EuropaBio, "Longer-term solutions should include a more efficient and rapid processing of GM products through the EU system but there are no indications things might improve soon." 